\title{
Rapamycin promotes the anticancer action of dihydroartemisinin in breast cancer MDA-MB-231 cells by regulating expression of Atg7 and DAPK
}

\author{
QIUJUN LIU ${ }^{1,2^{*}}$, XIANYAO ZHOU ${ }^{2 *}$, CHUAN LI $^{2}$, XUEMEI ZHANG ${ }^{2}$ and CHANG LONG LI ${ }^{2}$ \\ ${ }^{1}$ Department of Biochemistry and Molecular Biology, Southwest Medical University, Luzhou, Sichuan 646000; \\ ${ }^{2}$ Department of Biochemistry and Molecular Biology, West China School of Preclinical and Forensic Medicine, \\ Sichuan University, Chengdu, Sichuan 610041, P.R. China
}

Received February 26, 2017; Accepted December 4, 2017

DOI: $10.3892 /$ ol.2018.8013

\begin{abstract}
There is limited knowledge regarding the influence of autophagy on the anticancer effect of dihydroartemisinin (DHA). The present study aimed to investigate this influence within human breast cancer cells. Changes in cell viability, cell cycle distribution, apoptosis and associated genes were analyzed in MDA-MB-231 cells subjected to DHA following alteration in autophagy levels; the autophagy level was decreased following autophagy-related 7 (Atg7) knockdown or increased using rapamycin. The data indicated that rapamycin had the ability to notably enhance the anticancer effect of DHA on MDA-MB-231 cells. Autophagy induction may be key in mediating the anticancer effects of DHA, and rapamycin may regulate the death-associated protein kinase via the alteration of Atg7 expression, which would influence cell apoptosis. The present study presented a novel insight into enhancing the effectiveness of future treatment regimens for breast cancer using DHA.
\end{abstract}

\section{Introduction}

Dihydroartemisinin (DHA) is a semisynthetic derivative of artemisinin (ARS) isolated from the traditional Chinese herb Artemisia annua L.; it has been frequently used in the treatment of malaria $(1,2)$. Previous studies have reported that DHA also has potent antitumor effects; however, its anticancer mechanism is not well understood (3-6).

Correspondence to: Professor Chang Long Li, Department of Biochemistry and Molecular Biology, West China School of Preclinical and Forensic Medicine, Sichuan University, 17 People's South Road, Chengdu, Sichuan 610041, P.R. China

E-mail: changlongli@scu.edu.cn

${ }^{*}$ Contributed equally

Key words: dihydroartemisinin, breast cancer, MDA-MB-231, autophagy, rapamycin, autophagy-related 7 small interfering RNA
To date, a number of antitumor mechanisms that underlie the effects of DHA have been investigated. Lai et al (5) reported that ARS forms cytotoxic free radicals by reacting with iron to kill breast cancer cells in rats. It was also confirmed that DHA has the ability to slow the growth of breast tumors via a similar mechanism, as it is an analog of ARS (5). In a previous study, Noori and Hassan (6) demonstrated that DHA inhibited tumor growth through regulation of the immune response in the RIN cell line, and also inhibited the growth of tumor tissue in vivo. It was demonstrated that DHA exerts its anticancer action by increasing the expression of interferon- $\gamma$ and decreasing the level of interleukin-4 (6). The majority of reports concerning the mechanisms underlying DHA have focused on DHA-induced apoptosis $(7,8)$. Chen et al (7) reported that ARS and its derivatives, particularly DHA, were potently cytotoxic to human ovarian cancer A2780 and OVCAR-3 cells through the death receptor and mitochondrial-mediated caspase-dependent apoptotic pathways. Handrick et al (8) demonstrated that DHA induced the activation of caspases and DNA fragmentation in Jurkat T-lymphoma cells, which would induce apoptosis. In addition, DHA has been identified to induce autophagy in cancer cells: Hu et al (9) and Jia et al (10) demonstrated that DHA has the ability to induce autophagy and exert anticancer activities in cell lines of various types of cancer, including the human multiple myeloma cancer RPMI 8226 cell line, promyelocytic leukemia NB4 cell line, human colorectal cancer HCT116 cell line, human cervical cancer HeLa cell line and the human pancreatic cancer cell lines BxPC-3 (CRL-1687) and PANC-1 (CRL-1469).

Autophagy is an intracellular degradation process of dispensable material for cell survival when cells encounter environmental stresses, including nutrient starvation and pathogen infection (11-14). In recent years, autophagy has been considered to serve an important role in carcinogenesis, development and patient prognosis (12-17). It has been revealed that several autophagy-related (Atg) genes were involved in autophagosome formation (12-17). Autophagy is a protective mechanism that exerts antitumor action (13-17). For example, mice with the heterozygous mutant autophagy gene ATG6/BECN1 are prone to developing liver and lung tumors (13-17). Atg7 is known to serve a role in forming the 
autophagic vacuole (15-19). Conversely, the protective mechanism of autophagy can be utilized by cancer cells to overcome environmental stresses, including nutritional deficiency and the therapeutic use of anticancer drugs (19). Gonzalez et al (19) demonstrated that the anticancer action of MitoQ ${ }^{\circledR}$ was inhibited in the Atg7-deficient human MDA-MB-231 cell line. In the present study, RNAi technology was utilized to interfere with Atg7 expression to suppress autophagy.

It was assumed that the anticancer action of DHA would be affected by the level of autophagy; therefore, the associated changes to cell viability, expressions of associated genes and the cell cycle in breast cancer cells were observed when the level of autophagy was altered. Rapamycin is a lipophilic macrolide antibiotic that has the ability to induce autophagy in various cell types $(20,21)$; thus, in the present study, rapamycin was used to induce autophagy. Although the amount of data concerning autophagy and DHA is extensive, the association between the autophagy and DHA response in cancer cells remains unclear. The present study aimed to investigate the effect of autophagy on the anticancer action of DHA in MDA-MB-231 cells. Rapamycin and Atg7 small interfering RNA (siRNA) was used as inducer and inhibitor of autophagy, respectively. Following this, cell viability was detected by the MTT method (22), the expression levels of Atg7 and death-associated protein kinase (DAPK) were measured by reverse transcription-quantitative polymerase chain reaction (RT-qPCR) and the cell cycle distribution was estimated using flow cytometry. The present study revealed that the anticancer action of DHA is enhanced by rapamycin, but is reduced following Atg7 knockdown. DAPK is involved in membrane blebbing and the formation of autophagic vesicles in the process of cell death $(23,24)$. The expression of the DAPK1 gene was assessed when autophagy was altered in DHA-treated MDA-MB-231 breast cancer cells. It was demonstrated that rapamycin regulated the Atg7 gene and alter the expression of DAPK, which inhibited proliferation or promoted apoptosis in breast cancer MDA-MB-231 cells.

\section{Materials and methods}

Cell culture and reagents. MDA-MB-231 cells were provided by the National Key Laboratory of Molecular Biology Department, West China Medical Centre of Sichuan University (Chengdu, China). Rapamycin was obtained from Selleck Chemicals (Houston, TX, USA; cat no. S1039) and DHA was obtained from Shaanxi Sciphar Biotechnology Co., Ltd. (Xi'an, China). The cell lines were cultured in high-glucose Dulbecco's Modified Eagle's Medium (DMEM; Invitrogen; Thermo Fisher Scientific, Inc., Waltham, MA, USA) supplemented with $10 \%$ fetal bovine serum (Invitrogen; Thermo Fisher Scientific, Inc., Waltham, MA, USA) and $1 \%$ penicillin and streptomycin (both Invitrogen; Thermo Fisher Scientific, Inc.). When cells reached $\sim 80 \%$ confluence, the cells were seeded into 96 -well plates $\left(1 \times 10^{5} / \mathrm{ml}\right)$ and cultured for $20 \mathrm{~h}$. All cultures were maintained at $37^{\circ} \mathrm{C}$ in a humidified atmosphere containing $5 \% \mathrm{CO}_{2}$. Next, the cells were treated in groups, which included DHA alone $(10 \mu \mathrm{g} / \mathrm{ml})$, DHA (10 $\mu \mathrm{g} / \mathrm{ml})$ and rapamycin (100 $\mathrm{nmol} / \mathrm{l})$ (the rapamycin group), and Atg7-knockdown cells treated with DHA $(10 \mu \mathrm{g} / \mathrm{ml})$ (the Atg7-knockdown group). Each group was repeated three times in triplicate.
siRNA and transfection. MDA-MB-231 cells were transfected with 21-25 nt Atg7 siRNA at $100 \mathrm{nM}$ or negative-control (NC) siRNA Guangzhou RiboBio Co., Ltd., Guangzhou, China) using the Atg7 siRNA kit (cat no. RN:R10043.4) following the manufacturer's protocol once cells had been cultured for 24 h, using Lipofectamine ${ }^{\circledR}$ RNAiMAX Transfection Reagent (Invitrogen; Thermo Fisher Scientific, Inc.). The target sequence for Atg7 siRNA (cat no. 1294165753) was GGA GTCACAGCTCTTCCTT, and the primer sequences were as follows: Sense, 5'-GGAGUCACAGCUCUUCCUUdTdT-3' and antisense, 5'-AAGGAAGAGCUGUGACUCCTdTd-3'. Transfection efficiency was determined by detecting Atg7 expression levels with RT-qPCR. Following transfection for $4 \mathrm{~h}$, the medium was removed from all groups and the cells were washed twice with $0.01 \mathrm{~mol} / \mathrm{l} \mathrm{PBS}$. Next, the cells were re-cultured in DMEM (high-glucose) at $37^{\circ} \mathrm{C}$ in a humidified atmosphere containing $5 \% \mathrm{CO}_{2}$. Cells were then separated into 3 groups; i) DHA+Atg7(-) group, MDA-MB-231 cells transfected with Atg7-siRNA and treated with DHA $(10 \mu \mathrm{g} / \mathrm{ml})$; ii) DHA group, MDA-MB-231 cells treated with DHA alone (10 $\mu \mathrm{g} / \mathrm{ml})$; iii) DHA+Rapamycin(-) group, MDA-MB-231 cells treated with DHA $(10 \mu \mathrm{g} / \mathrm{ml})$ and rapamycin $(100 \mathrm{nmol} / \mathrm{l})$. Each group was repeated three times in triplicate. The time between transfection and subsequent experimentation was $4 \mathrm{~h}$.

$R N A$ preparation and $R T-q P C R$ analysis. Total RNA was isolated from cultured MDA-MB-231 cells with TRIzol ${ }^{\circledR}$ Reagent (Takara Biotechnology Co., Ltd., Dalian, China) following treatment for $24 \mathrm{~h}$. First-strand cDNA was synthesized using the Revert Aid ${ }^{\mathrm{TM}}$ First Strand cDNA Synthesis kit (Takara Biotechnology Co., Ltd., Dalian, China) according to the manufacturer's protocol. The method of analysis used in RT-qPCR followed a protocol described in a previous study (25). To determine the effectiveness of the Atg7 siRNA transfection, RT-qPCR was performed to detect Atg7 mRNA levels using the primers described previously (25) (Sangon Biotech Co., Ltd., Shanghai, China): Human Atg7, forward 5'-CTTTTTGCCAAC ATCCCTG-3' and reverse 5'-GGTCTCTGGTTGAATCTC CT-3'; reference gene human $\beta$-actin primers, forward 5'-GAA GATCAAGATCATTGCTCCT-3' and reverse 5'-TACTCCTGC TTGCTGATCCA-3'. Conditions for the RT-qPCR reactions were as follows: $2 \mathrm{~min}$ at $94^{\circ} \mathrm{C}$ followed by 40 cycles of $20 \mathrm{sec}$ at $94^{\circ} \mathrm{C}, 16 \mathrm{sec}$ at $54^{\circ} \mathrm{C}$ and $30 \mathrm{sec}$ at $72^{\circ} \mathrm{C}$. The gene expression results were analyzed using GraphPad Prism software version 5.01 (GraphPad Software, Inc., La Jolla, CA, USA). To detect mRNA levels of the target gene in autophagy- and cancer-associated pathways, the following primers (Shanghai Kehua Bio-engineering Co., Ltd.) were employed for qPCR using the same conditions as described previously (26): DAPK1, forward 5'-AGAAATTCAAGAAGTTTGCAG-3' and reverse 5'-GTCTTCCTCATCCAGAGTAT-3'.

Cell viability assay. The viability of each group were detected at $6,12,24,48$ and $72 \mathrm{~h}$ time points following treatment [either DHA alone $(10 \mu \mathrm{g} / \mathrm{ml})$; DHA $(10 \mu \mathrm{g} / \mathrm{ml})$ and rapamycin (100 nmol/l); or Atg7-knockdown cells treated with DHA $(10 \mu \mathrm{g} / \mathrm{ml})]$, and experiments were repeated 3 times. The media were removed from all groups and replaced with serum-free high-glucose DMEM. Next, MTT $(5 \mathrm{mg} / \mathrm{ml})$ was added into the wells and cultured at $37^{\circ} \mathrm{C}$ for $4 \mathrm{~h}$. 
When the medium of all groups was discarded, dimethyl sulfoxide was added into the wells (150 $\mu \mathrm{l} /$ well) and oscillated for $10 \mathrm{~min}$ to dissolve the formazan crystals. A colorimetric assay was performed using an ELISA reader (Supermax 3100 Plus; Shanghai Flash Biotechnology Co., Ltd., Shanghai, China) to determine the optical density value of each group at a wavelength of $490 \mathrm{~nm}$ (OD490). The number of living cells was proportional to the OD490, which was used to determine the cell viability.

Flow cytometry. MDA-MB-231 cells were inoculated on 6 well plates $(2 \mathrm{ml} / \mathrm{well})$ and cultured for $24 \mathrm{~h}$ at a concentration of $5 \times 10^{4} / \mathrm{ml}$ using DMEM (Invitrogen; Thermo Fisher Scientific, Inc.). Cells were then cultured at $7^{\circ} \mathrm{C}$ in $5 \% \mathrm{CO}_{2}$ and $95 \%$ saturated humidity following treatment by group as aforementioned [either DHA alone $(10 \mu \mathrm{g} / \mathrm{ml}) ;$ DHA $(10 \mu \mathrm{g} / \mathrm{ml})$ and rapamycin $(100 \mathrm{nmol} / \mathrm{l})$; or Atg7-knockdown cells treated with DHA $(10 \mu \mathrm{g} / \mathrm{ml})]$ for $24 \mathrm{~h}$. Subsequently, cells were harvested after 24 and $48 \mathrm{~h}$ and fixed with precooling $70 \%$ ethanol at $4^{\circ} \mathrm{C}$ for $1 \mathrm{~h}$. Cells were then centrifuged at $400 \mathrm{x} \mathrm{g}$ for $10 \mathrm{~min}$ at $4^{\circ} \mathrm{C}$, washed twice with $0.01 \mathrm{~mol} / \mathrm{l} \mathrm{PBS}$ solution, and incubated with $1 \mathrm{ml} 0.01 \mathrm{~mol} / \mathrm{l}$ PBS containing $100 \mu \mathrm{g} / \mathrm{ml}$ RNAase A (cat no. HZB0210; Sigma-Aldrich; Merck KGaA, Darmstadt, Germany) at $37^{\circ} \mathrm{C}$ for $30 \mathrm{~min}$. Subsequently, $75 \mu \mathrm{l}$ propidium iodide (Sigma-Aldrich; Merck KGaA) was added to $1 \mathrm{ml} 0.01 \mathrm{~mol} / 1 \mathrm{PBS}$ at a final concentration of $50 \mu \mathrm{g} / \mathrm{ml}$ and incubated at $4^{\circ} \mathrm{C}$ in dark room for $30 \mathrm{~min}$. Finally, BD FACS Calibur Flow cytometer (BD Biosciences, Franklin Lakes, NJ, USA) was used and cell cycle data was analyzed using BD FACSDiva software version 4.1 (BD Biosciences).

Statistical analysis. All results, unless otherwise indicated, are expressed as the mean \pm standard error of at least triplicate experiments. Data were analyzed using the GraphPad Prism software version 5.01. $\mathrm{P}<0.05$ was considered to indicate a statistically significant difference. Differences were evaluated using Student's t-test, or two-way repeated measures analysis of variance with Bonferroni's post hoc test. Information regarding autophagy pathways were obtained from the Kyoto Encyclopedia of Genes and Genomes (KEGG) (27).

\section{Results}

Rapamycin promotes the death of DHA-treated MDA-MB-231 cells whereas Atg7 deficiency increases the survival rate of DHA-treated MDA-MB-231 cells. MDA-MB-231 cells were treated with DHA-alone $(10 \mu \mathrm{g} / \mathrm{ml})$, DHA $(10 \mu \mathrm{g} / \mathrm{ml})$ and rapamycin $(100 \mathrm{nmol} / \mathrm{l})$, or DHA $(10 \mu \mathrm{g} / \mathrm{ml})$ and Atg7 siRNA. MDA-MB-231 cells were examined using an MTT assay $(6,12,24,48$ and $72 \mathrm{~h})$. Rapamycin decreased the viability of MDA-MB-231 breast cancer cells, whereas Atg7 knockdown increased cell viability (Fig. 1). The data demonstrated that rapamycin enhanced the anticancer action of DHA on this breast cancer cell line; therefore, rapamycin promoted the death of DHA-treated MDA-MB-231 cells. Hence, rapamycin-induced autophagy may promote the anticancer effect of DHA on breast cancer cells (Fig. 1).

Atg7 may indirectly upregulate DAPK expression and enhance autophagy. To investigate the effect of autophagy inhibition or induction on gene expression involved in the

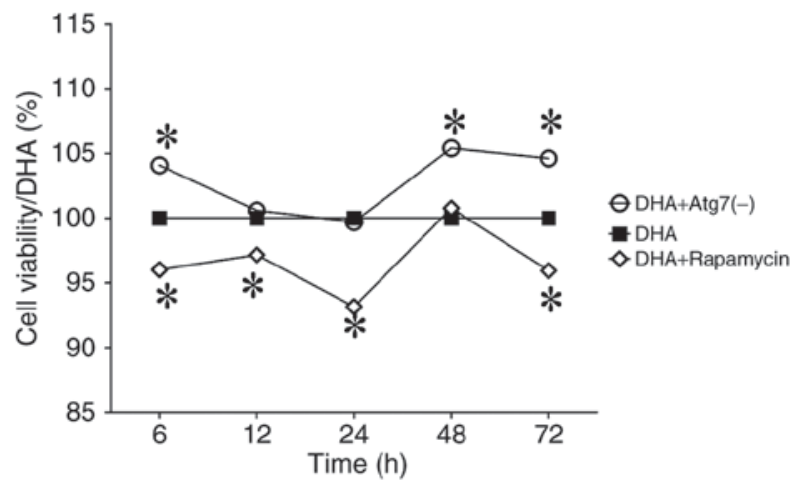

Figure 1. Autophagy induction promoted the death of DHA-treated MDA-MB-231 breast cancer cells. Rapamycin inhibited proliferation and Atg7 deficiency promoted survival in DHA-treated MDA-MB-231 breast cancer cells. MDA-MB-231 cells were examined an MTT assay (6, 12, 24, 48 and 72 h), normalized to the cell viability of control-MDA-MB-231 cells. This figure indicated that Atg7 knockdown increased the viability of MDA-MB-231 breast cancer cells and rapamycin decreased the viability. This graph indicates that Atg7 may function as a promoter of the anticancer effect of DHA. These data indicated that Atg7 knockdown facilitated the survival of MDA-MB-231 breast cancer cells, whereas rapamycin treatment enhanced the DHA action on this breast cancer cell line. DHA, dihydroartemisinin; Atg7, autophagy-related 7. ${ }^{*} \mathrm{P}<0.05$.

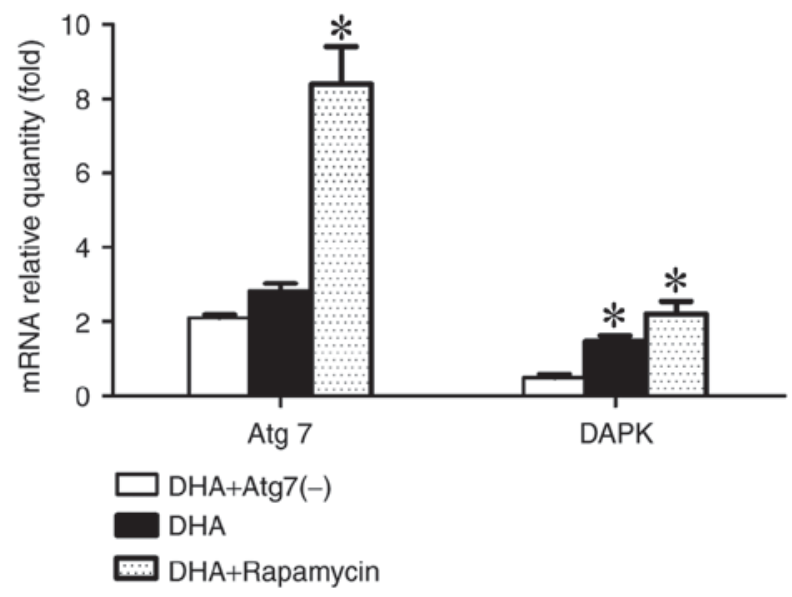

Figure 2. Atg7 may regulate DAPK to inhibit proliferation of the MDA-MB-231 cells. The mRNA levels of Atg7 increased, and DAPK changed accordingly. Atg7 and DAPK gene expressions in the DHA-treated MDA-MB-231 cells at $24 \mathrm{~h}$ were determined by reverse transcription-quantitative polymerase chain reaction ( $\beta$-actin was used as a reference). The expression levels of Atg7 and DAPK increased in the rapamycin group, and decreased in the Atg7-knockdown group. DHA, dihydroartemisinin; Atg7, autophagy-related 7; DAPK, death-associated protein kinase. ${ }^{\mathrm{P}}<0.05$.

cancer and autophagy pathways, the mRNA levels of Atg7 and DAPK were examined using RT-qPCR, with $\beta$-actin as the reference gene, following $24 \mathrm{~h}$ of the aforementioned treatments. Expression of Atg7 and DAPK was increased in the rapamycin group, whereas the expression levels decreased in the Atg7-knockdown group. The data demonstrated that the Atg7 gene may positively regulate DAPK expression via an unknown mechanism (Fig. 2).

Rapamycin promotes apoptosis in DHA-treated MDA-MB-231 breast cancer cells. To investigate the effect of DHA on the cell cycle and apoptosis following the induction or inhibition 
A

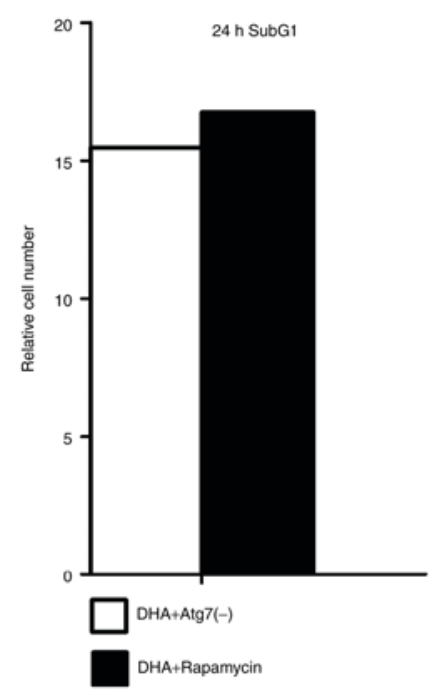

B

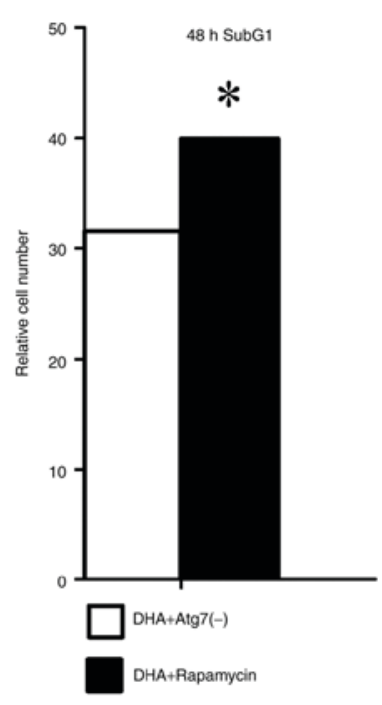

C
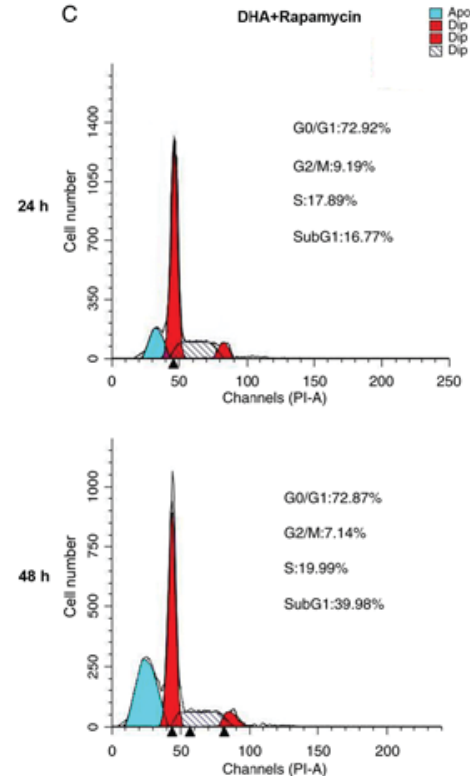

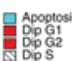
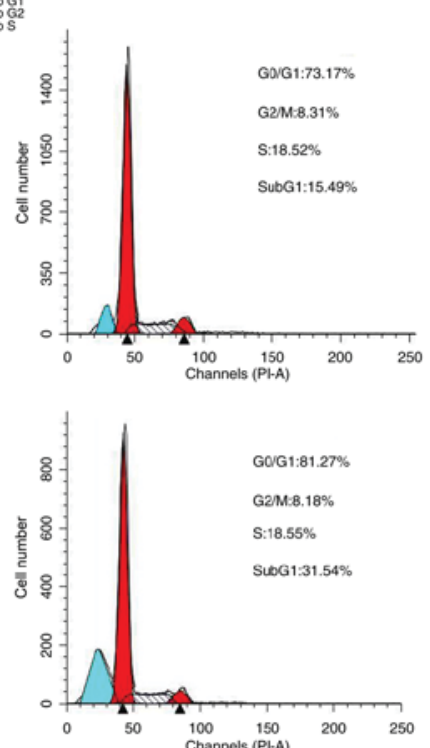

Figure 3. Rapamycin enhanced the pro-apoptotic effect of DHA in MDA-MB-231 cells. Cell cycle distribution and the proportion of apoptotic cells were detected using a flow cytometer at 24 and 48 h. (A) Cell numbers during the apoptotic phase (SubG ) $_{1}$ the MDA-MB-231 cells at 24 h. (B) Cell numbers during the apoptotic phase $\left(\mathrm{SubG}_{1}\right)$ in the MDA-MB-231 cells at $48 \mathrm{~h}$. Treatment with rapamycin notably promoted the effect of DHA on apoptosis at 24 and 48 h, compared with the Atg7 deficient group. (C) Cell cycle distribution and apoptosis graphs from flow cytometry. DHA, dihydroartemisinin; Atg7, autophagy-related 7; PI, propidium iodide. ${ }^{*} \mathrm{P}<0.05$.

of autophagy, the number of cells in each cell cycle phase was examined using a flow cytometer at 24 and $48 \mathrm{~h}$. Treatment with rapamycin notably increased the cell number in the apoptosis phase at 24 and $48 \mathrm{~h}$, which indicated that the induction of autophagy may be vital for apoptosis to occur in MDA-MB-231 cells. Compared with the rapamycin group, the cell number during the apoptosis phase was less in the Atg7-kncokdown group at each time point. Cell cycle arrest for all groups at 24 and $48 \mathrm{~h}$ occurred in the $\mathrm{G}_{0} / \mathrm{G}_{1}$ phase. The results indicate that rapamycin promoted apoptosis in DHA-treated MDA-MB-231 breast cancer cells (Fig. 3).

\section{Discussion}

In recent years, the anticancer effects of DHA have been demonstrated in a number of studies $(28,29)$. Zhang et al $(30)$ demonstrated that DHA can inhibit translationally controlled tumor protein (TCTP)-dependent cell migration and invasion by inhibiting TCTP and reducing cell division control protein 42 homolog (Cdc42) activation in the TCTP-positive cell lines NOZ, GBC-SD, OCUG-1 and EH-GB-1 in vitro. Additionally, this was also demonstrated in gallbladder cancer xenograft animal models established using a spleen-to-liver metastasis model in immunodeficient mice (30). Lemke et al (31) revealed that DHA exerted an anti-glioma activity, which included promotion of autophagy and induction of oxidative stress in the glioma cell lines LN-229 and LN-Z308 as well as in the primary T269 glioma cell line. The study indicated that DHA mildly inhibited the growth of glioma cells via the induction of autophagy, and that the anticancer effect of temozolomide was significantly enhanced following co-treatment with DHA in vitro and in vivo (31). Zhao et al (32) demonstrated that combined treatment with DHA and curcumin decreased cell viability, arrested the cell cycle and promoted apoptosis in human ovarian cancer SKOV3 cells. It was also identified that treatment with DHA alone has the ability to induce limited apoptosis, arrest the cell cycle at the $S$ and $G_{2} / M$ phases and inhibit tumor growth in a xenograft model established by subcutaneously injecting SKOV3 cells into the right flank of female BALB/c nude mice, without notable toxicity (32). Additionally, caspase-3 was not activated following treatment with DHA, and caspase-3 inhibitors did not inhibit cell apoptosis in any group; therefore, it was hypothesized that DHA may induce cell apoptosis via other apoptotic pathways (32). Consistent with these previous studies, the present study identified that DHA induced autophagy. Despite the presence of numerous studies (28-32), there is limited knowledge regarding the effect of autophagy on the anticancer action of DHA. The present study revealed the role of autophagy in the anticancer action of DHA within MDA-MB-231 cells. It was demonstrated that induction of autophagy using rapamycin promoted the death of DHA-treated MDA-MB-231 breast cancer cells, and Atg7 knockdown increased the survival rate of DHA-treated MDA-MB-231 cells. Furthermore, it was revealed that treatment with rapamycin notably increased the proportion of apoptotic cells at 24 and $48 \mathrm{~h}$, indicating that the induction of autophagy may be required for the apoptosis of MDA-MB-231 cells. Rapamycin has the ability to increase the expression of Atg7 and DAPK genes to enhance cell autophagy. Atg7 knockdown decreased the expression levels of DAPK, thus autophagy was inhibited. Existing data from the associated autophagy pathway in KEGG (27) indicated that increased expression of the DAPK gene has the ability to negatively regulate the ERK signaling pathway and therefore inhibit cell proliferation (27) and activate autophagy-associated pathways (27). The data demonstrated that DHA synergizes with rapamycin and promotes cell death and apoptosis via the upregulation of DAPK and Atg7, which provides an indication 
for its usefulness in anticancer studies and clinical application. In accordance with the results of other studies regarding DHA, the effects of DHA on autophagy were further confirmed (28-32). The present study provides novel evidence regarding the effects of rapamycin combined with DHA and Atg7 knockdown; however, owing to the limitations of in vitro experiments, the associated combined effects should be investigated in in vivo animal models in the future, with further cell lines investigated.

In conclusion, the present study demonstrated that rapamycin had the ability to promote cell death and apoptosis, and notably increased Atg7 and DAPK gene expression in MDA-MB-231 cells. Conversely, Atg7 knockdown facilitated cell survival and decreased Atg7 and DAPK gene expression in MDA-MB-231 cells. Previous studies have demonstrated that increased expression of the DAPK gene resulted in negative regulation of the ERK signaling pathway, which would inhibit cell proliferation; therefore, rapamycin may regulate the proliferation of MDA-MB-231 cells by increasing Atg7 gene expression, which in turn would increase DAPK gene expression levels. Consequently, it was considered that promoting autophagy may be vital in the anticancer effects of DHA, and that the regulation of the Atg7 expression levels may also influence DAPK expression levels.

\section{Acknowledgements}

The present study was funded by the Fostering Project of Sichuan Science and Technology Innovation Seedling Engineering (grant no. 20132048), the Project of the Education Department of Sichuan (grant no. 15ZA0159), the National Natural Science Foundation of China (grant no. H0815) and the Natural Project of Luzhou Medical College (grant no. 2014ZD-004). The authors would like to thank Doctor Liuqi Yang (National Key Laboratory of West China School of Sichuan University) for providing the MDA-MB-231 cells. The authors thank the Mr Qijie Li (Department of molecular genetics, West China School of Preclinical and Forensic Medicine, Sichuan University,) for technical assistance in flow cytometry.

\section{References}

1. Plucinski MM, Dimbu PR, Macaia AP, Ferreira CM, Samutondo C, Quivinja J, Afonso M, Kiniffo R, Mbounga E, Kelley JS, et al: Efficacy of artemether-lumefantrine, artesunate-amodiaquine, and dihydroartemisinin-piperaquine for treatment of uncomplicated Plasmodium falciparum malaria in Angola, 2015. Malar J 16: 62, 2017

2. Thanh NV, Thuy-Nhien N, Tuyen NT, Tong NT, Nha-Ca NT, Dong LT, Quang HH, Farrar J, Thwaites G, White NJ, et al: Rapid decline in the susceptibility of Plasmodium falciparum to dihydroartemisinin-piperaquine in the south of Vietnam. Malar J 16: 27, 2017.

3. Mao H, Gu H, Qu X, Sun J, Song B, Gao W, Liu J and Shao Q: Involvement of the mitochondrial pathway and $\mathrm{Bim} / \mathrm{Bcl}-2$ balance in dihydroartemisinin-induced apoptosis in human breast cancer in vitro. Int J Mol Med 31: 213-218, 2013.

4. Singh NP, Lai HC, Park JS, Gerhardt TE, Kim BJ, Wang S and Sasaki T: Effects of artemisinin dimers on rat breast cancer cells in vitro and in vivo. Anticancer Res 31: 4111-4114, 2011.

5. Lai H, Nakase I, Lacoste E, Singh NP and Sasaki T: Artemisinin-transferrin conjugate retards growth of breast tumors in the rat. Anticancer Res 29: 3807-3810, 2009.

6. Noori S and Hassan ZM: Dihydroartemisinin shift the immune response towards Th1, inhibit the tumor growth in vitro and in vivo. Cell Immunol 271: 67-72, 2011.
7. Chen T, Li M, Zhang R and Wang H: Dihydroartemisinin induces apoptosis and sensitizes human ovarian cancer cells to carboplatin therapy. J Cell Mol Med 13: 1358-1370, 2009.

8. Handrick R, Ontikatze T, Bauer KD, Freier F, Rübel A, Dürig J, Belka C and Jendrossek V: Dihydroartemisinin induces apoptosis by a Bak-dependent intrinsic pathway. Mol Cancer Ther 9: 2497-2510, 2010.

9. $\mathrm{Hu}$ W, Chen SS, Zhang JL, Lou XE, and Zhou HJ: Dihydroartemisinin induces autophagy by suppressing NF- $\mathrm{B}$ activation. Cancer Lett 343: 239-248, 2014

10. Jia G, Kong R, Ma ZB, Han B, Wang YW, Pan SH, Li YH and Sun B: The activation of c-Jun $\mathrm{NH}_{2}$-terminal kinase is required for dihydroartemisinin-induced autophagy in pancreatic cancer cells. J Exp Clin Cancer Res 33: 8, 2014.

11. Kumar D, Shankar S and Srivastava RK: Rottlerin-induced autophagy leads to the apoptosis in breast cancer stem cells: Molecular mechanisms. Mol Cancer 12: 171, 2013.

12. Desai S, Liu Z, Yao J, Patel N, Chen J, Wu Y, Ahn EE, Fodstad O and Tan M: Heat shock factor 1 (HSF1) controls chemoresistance and autophagy through transcriptional regulation of autophagy-related protein 7 (ATG7). J Biol Chem 29, 288: 9165-9176, 2013.

13. Wilson EN, Bristol ML, Di X, Maltese WA, Koterba K, Beckman MJ and Gewirtz DA: A switch between cytoprotective and cytotoxic autophagy in the radiosensitization of breast tumor cells by chloroquine and vitamin D. Horm Cancer 2: 272-285, 2011.

14. Levine B and Yuan J: Autophagy in cell death: An innocent convict? J Clin Invest 115: 2679-2688, 2005.

15. Qu X, Yu J, Bhagat G, Furuya N, Hibshoosh H, Troxel A, Rosen J, Eskelinen EL, Mizushima N, Ohsumi Y, et al: Promotion of tumorigenesis by heterozygous disruption of the beclin 1 autophagy gene. J Clin Invest 112: 1809-1820, 2003.

16. Yue Z, Jin S, Yang C, Levine AJ and Heintz N: Beclin 1, an autophagy gene essential for early embryonic development, is a haploinsufficient tumor suppressor. Proc Natl Acad Sci USA 100: 15077-15082, 2003.

17. Nemoto T, Tanida I, Tanida-Miyake E, Minematsu-Ikeguchi N, Yokota M, Ohsumi M, Ueno T and Kominami E: The mouse APG10 homologue, anE2-like enzyme for Apg12p conjugation, facilitates MAP-LC3 modification. J Biol Chem 278: 39517-39526, 2003.

18. Mizushima N, Yamamoto A, Hatano M, Kobayashi Y, Kabeya Y, Suzuki K, Tokuhisa T, Ohsumi Y and Yoshimori T: Dissection of autophagosome formation using Apg5-deficient mouse embryonic stem cells. J Cell Biol 152: 657-667, 2001.

19. Gonzalez Y, Aryal B, Chehab L and Rao VA: Atg7- and Keap1-dependent autophagy protects breast cancer cell lines against mitoquinone-induced oxidative stress. Oncotarget 5: 1526-1537, 2014.

20. Caramés B, Hasegawa A, Taniguchi N, Miyaki S, Blanco FJ and Lotz M: Autophagy activation by rapamycin reduces severity of experimental osteoarthritis. Ann Rheum Dis 71: 575-581, 2012.

21. Pan T, Rawal P, Wu Y, Xie W, Jankovic J and Le W: Rapamycin protects against rotenone-induced apoptosis through autophagy induction. Neuroscience 164: 541-551, 2009.

22. Montoro E, Lemus D, Echemendia M, Martin A, Portaels F and Palomino JC: Comparative evaluation of the nitrate reduction assay, the MTT test, and theresazurin microtitre assay for drug susceptibility testing of clinical isolatesof Mycobacterium tuberculosis. J Antimicrob Chemother 55: 500-505, 2005

23. Harrison B, Kraus M, Burch L, Stevens C, Craig A, Gordon-Weeks P and Hupp TR: DAPK-1 binding to a linear peptide motif in MAP1B stimulates autophagy and membrane blebbing. J Biol Chem 283: 9999-10014, 2008.

24. Inbal B, Bialik S, Sabanay I, Shani G and Kimchi A: DAP kinase and DRP-1 mediate membrane blebbing and the formation of autophagic vesicles during programmed cell death. J Cell Biol 157: 455-468, 2002.

25. Liu Q, Shi X, Zhou X, Wang D, Wang L and Li C: Effect of autophagy inhibition on cell viability and cell cycle progression in MDA-MB-231 human breast cancer cells. Mol Med Rep 10: 625-630, 2014

26. Overbergh L, Valckx D, Waer M and Mathieu C: Quantification of murine cytokine mRNAs using real time quantitative reverse transcriptase PCR. Cytokine 11: 305-312, 1999.

27. Kyoto Encyclopedia of Genes and Genomes (KEGG): hsa05200: Pathways in cancer. KEGG source record: clv04140: Regulation of autophagy. http://www.kegg.jp/kegg-bin/highlight_pathway?scale=1.0 \&map=map04140\&keyword=autophagy. Accessed January 17, 2018. 
28. Du XX, Li YJ, Wu CL, Zhou JH, Han Y, Sui H, Wei XL, Liu L, Huang P, Yuan $\mathrm{HH}$, et al: Initiation of apoptosis, cell cycle arrest and autophagy of esophageal cancer cells by dihydroartemisinin. Biomed Pharmacother 67: 417-424, 2013.

29. Wu GS, Lu JJ, Guo JJ, Huang MQ, Gan L, Chen XP and Wang YT: Synergistic anti-cancer activity of the combination of dihydroartemisinin and doxorubicin in breast cancer cells. Pharmacol Rep 65: 453-459, 2013.

30. Zhang F, Ma Q, Xu Z, Liang H, Li H, Ye Y, Xiang S, Zhang Y, Jiang L, Hu Y, et al: Dihydroartemisinin inhibits TCTP-dependent metastasis in gallbladder cancer. J Exp Clin Cancer Res 36: 68, 2017.
31. Lemke D, Pledl HW, Zorn M, Jugold M, Green E, Blaes J, Löw S, Hertenstein A, Ott M, Sahm F, et al: Slowing down glioblastoma progression in mice by running or the anti-malarial drug dihydroartemisinin? Induction of oxidative stress in murine glioblastomatherapy. Oncotarget 7: 56713-56725, 2016.

32. Zhao J, Pan Y, Li X, Zhang X, Xue Y, Wang T, Zhao S and Hou Y: Dihydroartemisinin and curcumin synergistically induce apoptosis in SKOV3 cells via upregulation of MiR-124 targeting midkine. Cell Physiol Biochem 43: 589-601, 2017. 